\title{
DeVElopment ANd Optimization Of an AutOMATEd IRRIgation SYStem
}

Submitted: 15 January 2019; accepted 23 February 2019

\section{Lanre Daniyan, Ezechi Nwachukwu, Ilesanmi Daniyan, Okere Bonaventure}

DOI: 10.14313/JAMRIS_1-2019/5

\begin{abstract}
:
The deployment of appropriate technologies to enhance modern agricultural practices and improve crop yields is imperative for sustainability. This paper presents the development of a standalone automated irrigation system. The system design features good automation and control, which was achieved using an array of electronic timing system, soil feedback sensor and wireless communication system. Autonomous irrigation events are based on the states of the timing system, the soil feedback system and the wireless communication system. The control and automation of these systems was done using an AVR microcontroller, which was programmed to trigger intelligent and independent farm irrigation operation through a water pump attached to the system. The system also operates remotely via SMS command from mobile device and sends operational status feedback via SMS to preprogrammed mobile user(s). It also sends soil moisture condition to a remote user upon query. The system package was produced using additive manufacturing technique. The power supply system was implemented using solar power system in order to achieve a standalone, autonomous and reliable power supply necessary for an independent operation. The performance evaluation of the developed system show impressive response time, good reliability and excellent stability. Furthermore, the numerical experiment conducted using the Response Surface Methodology (RSM) produced a mathematical model for the optimization of the irrigation process for optimum performance and cost effectiveness.
\end{abstract}

Keywords: Additive manufacturing, Automation, Irrigation, Intelligent system, Microcontroller

\section{Introduction}

The development of appropriate technologies in modern agricultural practices have not only improved crop yields but have also increased the ease with which farming practices are being done especially with the advent of robotic tools. With the increasing awareness and advocacy for round - the - year farming, and the need to meet up with the challenge of global food demand, deploying appropriate technologies to increase productivity and reduce the burden often associated with farm practices has become inevitable. Since the role of agriculture in the economic development of any nation cannot be overemphasized, there is need boost agricultural productivity with the use of intelligent systems for increased food production and revenue generation [1-2]. One of such areas in agricultural practices that has posed much burden, wasted useful times and resources is farm irrigation. Irrigation is the artificial application of water to the land or soil which assist in the growing of agricultural crops, maintenance of landscapes, and revegetation of soils in dry areas as well as during periods of inadequate rainfall [3-5]. Mainly, there are two types of irrigation systems namely; sprinkler [6-7] and drip irrigation system [8-9]. The use of the sprinkler irrigation system involves the spraying of water into the air with the aid of a pumping system and sprinkler, which falls on the crops in form of small drops of water like the rain. It finds suitable application in farm rows or fields either uniform or undulating [10]. On the other hand, the drip irrigation involves the passage of water directly to the root of plants from or below the soil surface using pipes or tubes. This form of irrigation is highly effective and conservative and most suitable in areas with acute shortage of water supply [11]. With regards to the challenges posed by conventional irrigation practices, the use of intelligent systems for irrigation are better appreciated particularly with large-scale farming. Conventional methods of irrigation are labour intensive, time-consuming, relatively ineffective due to poor water distribution and lack of monitoring as well as smart control mechanisms [12-13]. Its over-reliance on human control makes it not suitable for large-scale farming [14-16]. Automatic irrigation systems on the contrary are neither laborious nor time-consuming and can help meet the ever increasing demand for food production all the year round [17-18]. In addition, the process is cost effective in the long run as the initial capital invested will be offset via large scale farming to meet the increasing demand for food production [19-20]. The burden the automated irrigation system seeks to resolve is the ability to intelligently and independently irrigate the farm environment. As such, farmers can commit the time hitherto wasted on prolonged and laborious manual irrigation to other productive tasks while the system independently executes the irrigation process. According to Ganturi [21] and Curtis [22], the requirements for a smart irrigation system includes the effective application and distribution of water as well as good control and monitoring of the process of irrigation with appropriate feedback mechanisms. Karim et al. [23] 
developed a sensor-based M2M agriculture monitoring systems for developing countries citing high level of automation and control as one of the challenges to be addressed. Also, Alagupandi et al. [24] developed a smart irrigation system for outdoor environment using TinyOS while Gutierrez [25] developed an automated irrigation system using a wireless sensor network and GPRS module. These works provided a convenient platform for automation, control and tracking of irrigation activities. Mrinmayi et al. [26] also developed a smart irrigation system using internet of things while Roy and Ansari [27], developed autonomous irrigation systems that uses every day climate criterion for irrigation purpose. This helps in saving considerable amount of water for irrigation via the use of Programmable Logic Controller (PLC). The issue of water loss due to precipitation has been identified as one of the major challenges during the irrigation process. In a bid to address this challenge, Kumar et al. [28] developed an automatic irrigation system that uses field sensing and forecasting in an attempt to control irrigation based on soil moisture for the sustainable irrigation of crops. For effective distribution and control of water irrigation activities, Bai and Liang [29] as well as Li-Fang [30] developed an optimal model for water conservation. The parameters that are essential in order to facilitate good monitoring and control are; temperature, air humidity and soil moisture [30-35]. The design objectives of the developed automated irrigation system are to achieve operational intelligence, automation and independence thereby easing the stress often associated with conventional irrigation practices. The novelties of this work lies in the fact that the ease of operation of the developed automated system comes with its multiple modes of operation, which affords the user convenient choices of operation. The modes include the full automation mode whereby the system operates autonomously using the states of the timing system and the soil feedback sensor to take intelligent decisions on appropriate time and extent of irrigation activities to be implemented. In addition, a user could send a command remotely via mobile phone to the field system to start or stop irrigation. Furthermore, users have the privilege of querying the system remotely in order to get feedback on the real time soil conditions. Upon receiving such command via the Short Message Service (SMS), the system queries the soil feedback sensor and sends the soil moisture readings to the authorized user(s). The system can also be made to operate in the manual mode relying on human effort or semi autonomously relying on human control during certain periods such as the start up or shut down based on the environment and nature of irrigation activities to be carried out. The aforementioned peculiarities of the developed automated irrigation system have not been sufficiently reported by the existing literature.

\section{Materials and Method}

The materials employed in the implementation of this system are real time clock module, YL - 69 sensor, SIM800L, Atmega328 microcontroller, DC water pump, PV module, LM6009 module, LM 2596 module,
Lipo cells, LCD, switches, relay, LED, resistors, capacitors, crystal Oscillator, active SIM card, filament for additive manufacturing, metal frame for PV and control unit.

The capability of the automated irrigation system include the ability to take intelligent decisions on its state, based on operational and soil conditions. Also, the solar power provision will enable it sustain a continuous operation at all times and to achieve high reliability in its operations. The need for irrigation tend to increase with increase in solar energy usually accompanied by soil moisture loss. Hence, the solar energy can be trapped for powering the autonomous system.

\subsection{System Architecture}

The architecture of the developed system is presented in Figure 1.

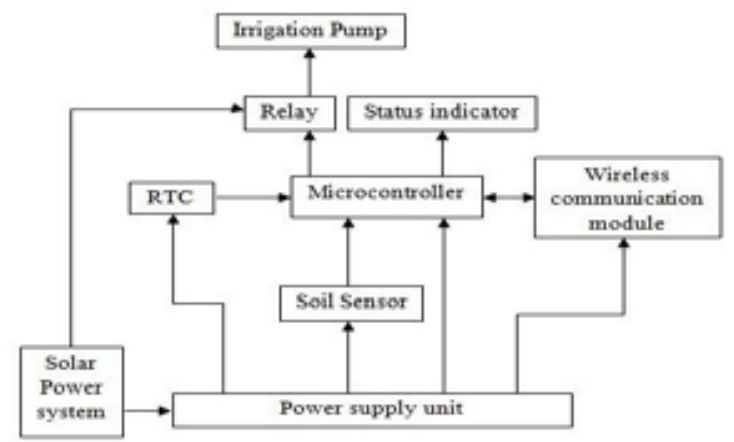

Fig. 1. Architecture of the automated irrigation system

\subsection{Automation and Control}

Generally, irrigation exercise is usually carried out in the morning or evening hours for the sake of the health of farm crops. The pre-programmed time for irrigation was done and stored on the micro controller. Hence, the microcontroller routinely checks for this time with respect to the environmental conditions. A DS1307 timing system also known as the real time clock was incorporated to give an accurate track of the date and time of the irrigation activities (Figure 2).

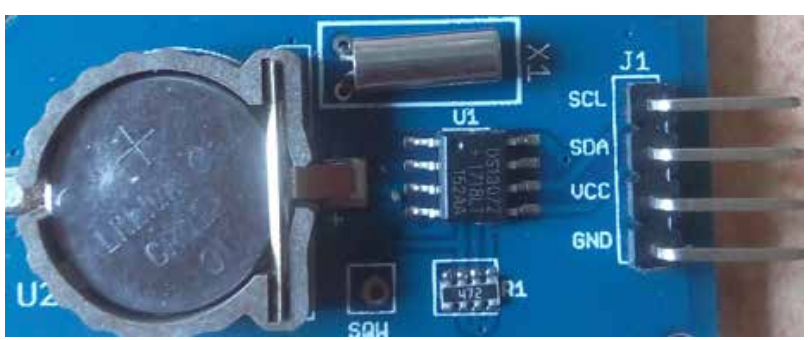

Fig. 2. DS1307 timing system

According to the programming of the microcontroller, there will be need for irrigation only if the soil moisture goes below $25 \%$ and such irrigation operation is halted if the farm is irrigated up to $50 \%$. Therefore, the microcontroller keeps its check for the environmental conditions in respect of the pre-set time most especially when the humidity drops below 
$25 \%$. Anytime these two conditions are active, a relay is activated to switch the irrigation pump ON. A Short Message Service (SMS) alert is sent to the authorized user on the state of the pump and the active mode of control. The authorized user receives a message "Pump ON", and Control mode: "Auto". At any condition outside the aforementioned operational limits, the pump state is kept "OFF", and the state indicates "Idle". These are designed to take place without the users' input. In addition, users can send a message "ON" from a mobile phone to the SIM number in the system. Upon receiving this message, the system activates the relay which will in turn activate the irrigation pump. The state changes to "Pump ON" and the control mode changes to "Remote". The state is sent as feedback to the remote operator's mobile phone. Upon receiving the message "OFF" from the user, the pump goes off and the state returns to "Idle". This would equally be sent as feedback to the users' mobile phone. The user also has the privilege to query the system via a simple SMS command to get the real time soil moisture reading, which will be sent as a message from the system to the users' mobile phone. In the event of an emergency need of water on site, such as in the case of washing harvested farm crops, a manual mini switch is provided for the pump on - site. The Light Emitting Diode (LED) goes "OFF" in the idle state, "BLUE" in the remote control state, "GREEN" in the timing or soil automation state and "RED" in manual operation mode. One of the peculiarities of this system is that users have the privilege of querying the system remotely in order to get feedback on the real time soil conditions. Upon receiving such command via the SMS, the system queries the soil feedback sensor and sends the soil moisture readings to authorized user(s). For the purpose of this work, only one moisture sensor was used and this is shown in Figure 3. The features of the soil moisture sensor include: power supply (3.3 V-3.5 V), output voltage (0-4.2 V), current $3.5 \mathrm{~mA})$, size $(60 \times 20 \times 5 \mathrm{~mm})$. It comprises of two probes which passes current into the soil and thereafter reads the electrical resistance so as to determine the moisture level. High moisture content in the soil often triggers high conductivity of electricity by the soil and vice versa. The output voltage from the soil moisture sensor is then amplified and sent to the micro controller where it is converted to digital using Analogue to Digital Converter (ADC). On the controller, the voltage is compared to the threshold value pre-set on it, if the measured voltage is less than the threshold value, the micro controller activates the relay which turns $\mathrm{ON}$ the pump for irrigation activities. On the other hand, if the measured value exceeds or

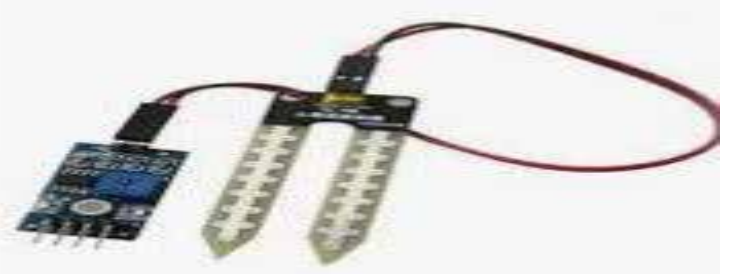

Fig. 3. The soil moisture sensor equal to the threshold, it implies there is no need for irrigation hence system remains in the idle state with the LED indicating "OFF".

\subsection{Power Provisioning}

For a continuous and reliable operation of this system, an independent power supply is essential. As such, a PV module, which was scaled relative to the power requirement of the DC operated irrigation pump, was deployed. The control unit is equipped with a 10,500 mAH lithium ion battery backup to keep the system active at night. The power supply unit of the system is designed to take power also from the PV installation and provision power according to power requirement of the control sub - systems as shown in Figure 4.

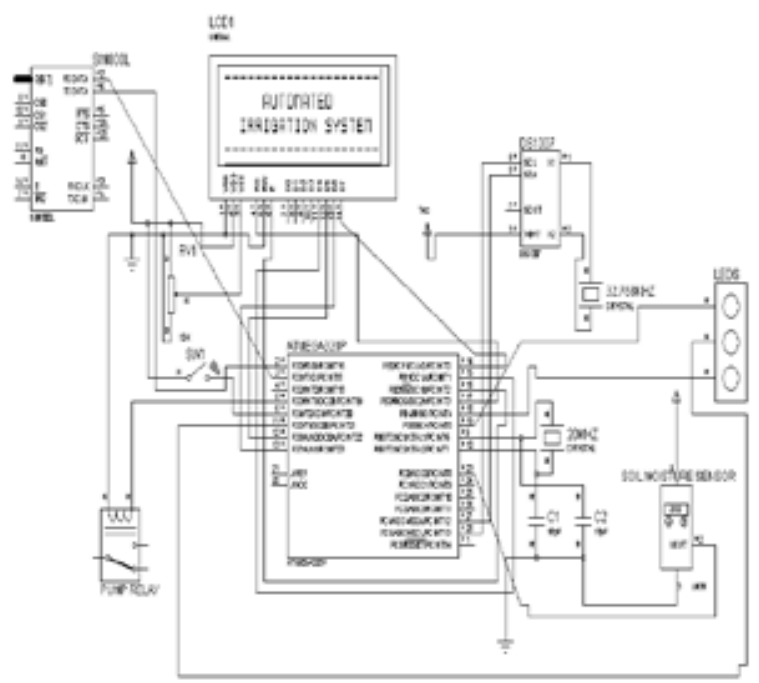

Fig. 4. Proteus design model of the automated irrigation system

\subsection{Packaging and Product Outlook}

The product outlook was first designed in the Computer Aided Design (CAD) environment (Figure 5) and produced with the aid of additive manufacturing technique (Figure 6).

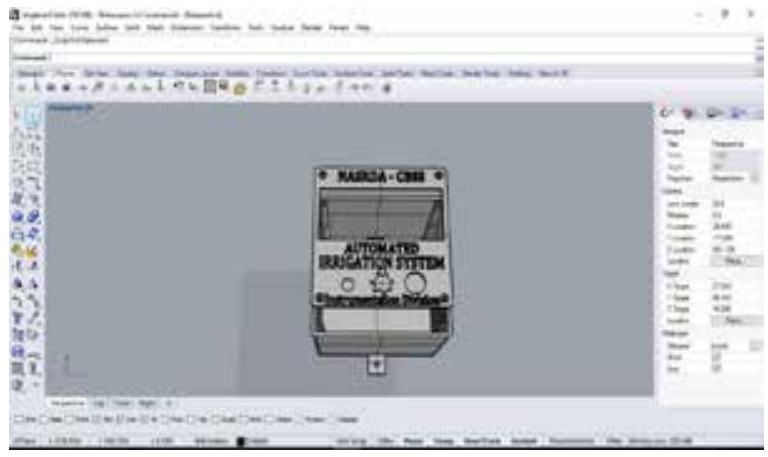

Fig. 5. CAD of the system

For simplified installation or ease of decommissioning, interfaces were created at the side of the system unit where the PV module, the DC water pump and the soil moisture feedback sensor were wired onto the system. 


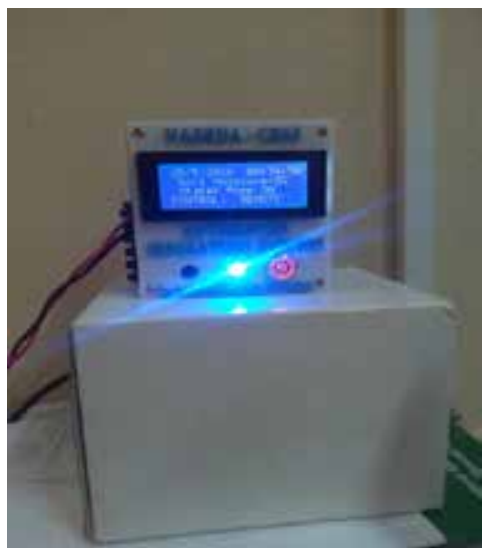

Fig. 6. The automated irrigation system

\subsection{Design Calculations}

The volume of water pumped was $750 \mathrm{~L} / \mathrm{hr}$ which is adequate for the small experimental farm, hence the volumetric flow rate is calculated as $2.08 \times 10^{-4} \mathrm{~m}^{3} / \mathrm{sec}$. For a pumping operation expected to last for 1 hour (3600 secs), the total volume of water pumped is calculated from Equation 1.

$$
\begin{gathered}
Q=\frac{V}{t} \\
1.94 \times 10^{-5}=\frac{V}{3600} \\
V=0.750 \mathrm{~m}^{3}(750 \mathrm{~L})
\end{gathered}
$$

Using a $25 \mathrm{~mm}(0.025 \mathrm{~m})$ diameter pipe to convey the water, the area of the pipe is calculated from Equation 2.

$$
A=\frac{\pi d^{2}}{4}
$$

The area of the pipe from Equation 2 is calculated as $4.90 \times 10^{-4} \mathrm{~m}^{2}$.

Since the volumetric flow rate is a function of the velocity and cross sectional area, Equation 3 holds thus,

$$
Q=v A
$$

Where; $Q$ is the volumetric flow rate calculated as $750 \mathrm{~L} / \mathrm{hr},\left(2.08 \times 10^{-4} \mathrm{~m}^{3} / \mathrm{sec}\right)$ and $\mathrm{v}$ is fluid velocity (m/s). Hence, the fluid velocity from Equation 3, is calculated thus,

$$
\begin{gathered}
2.08 \times 10^{-4}=v \times 4.90 \times 10^{-4} \\
v=0.424 \mathrm{~m} / \mathrm{s}
\end{gathered}
$$

The Reynold's number, which determines the nature of flow, is expressed as Equation 4.

$$
R e=\frac{\rho v d}{\mu}
$$

$v$ is the fluid velocity $(0.424 \mathrm{~m} / \mathrm{s}) ; \rho$ is the water density $\left(1000 \mathrm{~kg} / \mathrm{m}^{3}\right), d$ is the pipe diameter $(0,025 \mathrm{~m})$ and $\mu$ is the coefficient of dynamic viscosity for water at temperature of $25^{\circ} \mathrm{C}\left(8.9 \times 10^{-4} \mathrm{Ns} / \mathrm{m}^{2}\right)$

$$
R e=\frac{1000 \times 0.424 \times 0.025}{8.9 \times 10^{-4}}
$$

$$
R e=11910.11
$$

Since $R e>4000$, the flow of water for the irrigation purpose is turbulent. The advantage of turbulent water flow for irrigation is that water is dispatched quickly through the conveying pipe at high velocities and flow rates thereby driving the irrigation process to quick completion.

Neglecting the minor losses due to pipe orientation, the frictional factor for losses in a flexible rubber pipe with smooth bore is expressed by Equation 5 [35].

$$
\begin{gathered}
f=\left[\frac{0.0076\left(\frac{3170}{\mathrm{Re}}\right)^{0.165}}{1+\left(\frac{3170}{\mathrm{Re}}\right)^{7.0}}\right]+\frac{16}{R e} \\
f=\left[\frac{0.0076\left(\frac{3170}{11910.11}\right)^{0.165}}{1+\left(\frac{3170}{11910,11}\right)^{7.0}}\right]+\frac{16}{11910.11} \\
f=0.0075
\end{gathered}
$$

The major head loss $H$ due to this frictional effect is expressed by Equation 6 [36].

$$
H=\frac{4 f l v^{2}}{D .2 g}
$$

Where; $f$ is the frictional factor $(0.825), v$ is the length of the pipe $(1000 \mathrm{~m}) ; v$ is the fluid velocity $(0.424 \mathrm{~m} / \mathrm{s}) ; g$ is the acceleration due to gravity $\left.9.81 \mathrm{~m} / \mathrm{s}^{2}\right), d$ is the pipe diameter $(0.025 \mathrm{~m})$

$$
\begin{gathered}
H=\frac{4 \times 0.0075 \times 1000 \times 0.424^{2}}{0.025 \times 2 \times 9.81} \\
H=10.99 \mathrm{~m} \text { of water }
\end{gathered}
$$

Equation 7 expresses the density of a fluid.

$$
\operatorname{density}(\rho)=\frac{\text { mass }}{\text { volume }}
$$

Water density $(\rho)$ is $1000 \mathrm{~kg} / \mathrm{m}^{3}$ and volume $V$ is $0.750 \mathrm{~m}^{3}$, hence, from Equation 7, the mass of fluid is calculated as $570 \mathrm{~kg}$.

According to Rajput (2008), the power required to pump fluid is given by Equation 8 .

$$
P=\rho g Q H
$$

where: $\rho$ is the water density $\left(1000 \mathrm{~kg} / \mathrm{m}^{3}\right), g$ is the acceleration due to gravity $\left(9.81 \mathrm{~m} / \mathrm{s}^{2}\right), Q$ volumetric flow rate $\left(2.08 \times 10^{-4} \mathrm{~m}^{3} / \mathrm{sec}\right)$ and $H$ is the pumping head, $(12.09 \mathrm{~m})$ :

$$
\begin{gathered}
P=1000 \times 9.81 \times 2.08 \times 10^{-4} \times 10.99 \\
P=22.5 \mathrm{~W}
\end{gathered}
$$

The power required to pump the fluid is calculated from Equation 8 as $22.5 \mathrm{~W}$ and a $50 \mathrm{~W}$ (0.067 hp) pump is selected using a safety factor of 2.2 The system is energy efficient in that it needs only $50 \mathrm{~W}$ of power to pump fluid. The pump will increase the temperature of the fluid stream as given in Equations 9 and 10 . 


$$
\begin{gathered}
q=m c_{p} \Delta T \\
P t_{p}=m c_{p} \Delta T
\end{gathered}
$$

where: $q$ is the heat input $(\mathrm{kJ}), P$ is the required power of the pump (kW), $t_{p}$ is the time required to run pump, (sec), $\mathrm{m}$ is the mass of water, $(\mathrm{kg}), C_{p}$ is the specific heat capacity, $(\mathrm{kJ} / \mathrm{kgK})$, and $\Delta T$ is the change in temperature, (Kelvin).

For a pump whose required power is $25 \mathrm{~W}$, running for $3600 \mathrm{sec}$ and the mass of water is $750 \mathrm{~kg}$ with specific heat capacity of $4200 \mathrm{~J} / \mathrm{kgK}$, the change in temperature is obtained using Equation 9.

$$
25 \times 3600=750 \times 4200 \times \Delta T
$$

$$
\Delta T=0.0287^{\circ} \mathrm{C}
$$

At equilibrium, the temperature of water equals the room temperature $25^{\circ} \mathrm{C}$. From Equation 10, the pump will increase the temperature by $0.0287^{\circ} \mathrm{C}$, hence the final temperature of water for irrigation is $25.0287^{\circ} \mathrm{C}$. This falls within the safe limit of the water temperature for irrigation.

The current demand of the pump is expressed by Equation 10.

$$
P=I V
$$

Where $P$ is the power required by the pump $(50 \mathrm{~W})$; $I$ is the current required $(\mathrm{A})$ and $V$ is the applied voltage $24 \mathrm{~V}$

$$
\begin{aligned}
& 50=I \times 24 \\
& I=2.083 \mathrm{~A}
\end{aligned}
$$

\subsection{Performance Evaluation of the Developed Automated Irrigation System}

For large farms, pump sizing can be easily done by estimating the water volume requirements of the farm. This would also entail appropriate sizing of the solar power system to deliver required power to the irrigation pump. Also, the ampere rating of the switching relay in the control system will be matched adequately with the current demand of the pump. The operational indices show that it takes the system about 25 secs to boot up when powered ON and about 5 secs to receive a message instruction for pump activation. The solar power system delivers about $300 \mathrm{~W}$, with the feedback response time from the soil moisture sensor about 0.5 secs and the volume of water pumped approximately $750 \mathrm{~L} / \mathrm{hr}$ which is adequate for small experimental farm. The smart irrigation monitoring is embedded with soil moisture sensor to sense and obtain the values of moisture for any location to be irrigated. This is a critical factor which provides information about the condition of the soil to be irrigated so as to determine the need for irrigation or otherwise as well the quantity of water needed for irrigation. The system also provides irrigation data in terms of the volume of water used for irrigation, period of irrigation as well as the total time spent on irrigation, hence the development of the smart irrigation system provides design data for prediction and forecasting as well secondary data scaling its development or subsequent redesign.

\subsection{Numerical Experiment}

In order to develop a predictive model for the determination of volume of required for irrigation and study the effect of three critical factors that influences the water requirement of the soil namely; soil moisture, ambient air temperature and humidity, the dynamic modelling and simulation was carried out using the Response Surface Methodology (RSM). While the ambient air temperature accounts for the overall temperature of the outdoor air where the irrigation activity is to be performed, humidity represents the amount of water vapour present in the air. A multifunctional temperature and humidity measurement device (PCE-THA 10-ICA) whose temperature measurement ranges from -15 to $50^{\circ}$ and humidity measurement ranges between 5-95\% was employed for measuring both the temperature and the humidity of the environment where irrigation activity is to be performed. The range of values of three critical parameters namely; moisture content $(20-40 \%)$, ambient temperature $\left(15-35^{\circ} \mathrm{C}\right)$ and humidity $(10-30 \%)$ were used as input parameters into the Central Compose Design (CCD) and Response Surface Methodology (RSM) to develop a predictive model that correlates the volume of water required for irrigation purpose as a function of the three critical parameters. The essence of optimization is to provide an optimum solution for irrigation purpose. The optimum solution include the determination of the need for irrigation and the right volume of water required. This will save water, time and cost thereby promoting effective irrigation process.

\section{Results and Discussion}

The irrigation of small farm land of cross section $100 \mathrm{~m} \times 100 \mathrm{~m}$ was carried for three different soil samples namely; sandy, loamy and clay soil at five different locations between 8:00-8:59 am. The data collected from the soil moisture sensor, the multifunctional temperature and humidity measurement device and the micro controller are presented in Table 1.

Figure 7 is a plot of volume of water used and the time spent for the irrigation for the three soil samples. Three critical factors namely; soil moisture, ambient temperature and humidity determined the volume of water required for irrigation. The water requirement was highest in sandy soil and least in clay soil. This is due to the fact that the moisture content is highest in clay and least in sandy soil. The clay soil has high water retention ability due to its structure hence the reason for the high value of its moisture content, followed by loamy soil and then sandy soil. The requirement of water by the soil was observed to increase as the value of soil moisture decreases.

The equation of the predictive model is expressed by Equation 11:

$$
\begin{aligned}
\text { Volume }= & +759.43-284.97 A-7.69 B- \\
& 0.88 C+31.25 A \times B+21.25 A \times C \\
& +83.44 A^{2}-3.18 B^{2}+4.78 C^{2}
\end{aligned}
$$

where; $A$ is the percent soil moisture, $B$ is the ambient temperature $\left({ }^{\circ} \mathrm{C}\right)$ and $C$ is the percent humidity. 
Tab. 1. Results obtained for five different locations

\begin{tabular}{|c|c|c|c|c|c|c|c|}
\hline $\mathrm{S} / \mathrm{N}$ & Soil type & $\begin{array}{c}\text { Soil } \\
\text { sample }\end{array}$ & $\begin{array}{l}\text { Initial moisture } \\
\text { content (\%) }\end{array}$ & $\begin{array}{c}\text { Ambient } \\
\text { Temperature }\left({ }^{\circ} \mathrm{C}\right)\end{array}$ & $\begin{array}{c}\text { Humidity } \\
(\%)\end{array}$ & $\begin{array}{l}\text { Volume of water used } \\
\text { for irrigation (L) }\end{array}$ & $\begin{array}{l}\text { Total time spent } \\
\text { for Irrigation (sec) }\end{array}$ \\
\hline 1. & Clay & A & 22 & 24.5 & 17.2 & 230 & 690 \\
\hline 2. & Clay & B & 21 & 24.9 & 16.5 & 200 & 720 \\
\hline 3. & Clay & $\mathrm{C}$ & 23 & 22 & 18 & 155 & 640 \\
\hline 4. & Clay & D & 24 & 21.7 & 19.5 & 140 & 610 \\
\hline 5. & Clay & $\mathrm{E}$ & 21 & 24.2 & 17.5 & 151 & 600 \\
\hline 6. & Loamy & A & 19 & 25 & 16 & 245 & 980 \\
\hline 7. & Loamy & B & 20 & 24.5 & 17.2 & 220 & 930 \\
\hline 8. & Loamy & $\mathrm{C}$ & 20 & 23.8 & 18 & 205 & 895 \\
\hline 9. & Loamy & D & 18 & 24 & 16 & 169 & 876 \\
\hline 10. & Loamy & E & 19 & 23 & 16.2 & 150 & 800 \\
\hline 11. & Sandy & A & 17 & 23.5 & 16 & 260 & 985 \\
\hline 12. & Sandy & B & 16 & 24 & 15.6 & 250 & 960 \\
\hline 13. & Sandy & C & 18 & 22 & 16.8 & 230 & 920 \\
\hline 14. & Sandy & D & 17 & 23 & 16.3 & 265 & 1400 \\
\hline 15. & Sandy & E & 18 & 21.5 & 19 & 275 & 1200 \\
\hline
\end{tabular}

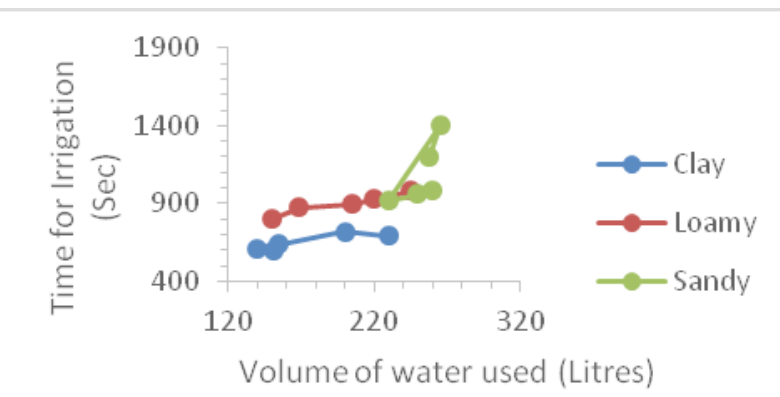

Fig. 7. Volume of water required and time for irrigation

The developed model was validated using the Analysis of Variance (ANOVA). It was found to be highly adequate for the prediction of the volume of water needed for irrigation as the regression model was found to be highly significant at 95\% confidence level. The correlation coefficients namely; the R-squared (0.9695), adjusted R-squared (0.9533) and predicted R-squared (0.9785) were within the same range and very close to 1 for input parameters. The closer the correlation coefficients to 1 , the more efficient and reliable the predictive ability of developed model.

Figure 8 is a 3 D plot that studies the effect of the interaction of humidity and temperature on the need for irrigation as well as the volume of water required. Humidity is the amount of water vapour present in the air. It is high when the amount of water vapour in the air is high while the ambient temperature is the degree of hotness or coldness of the air in the environment.

Humidity increases as the amount of water vapour in the air is increases. From Figure 8, the relationship between the humidity and temperature is inversely proportional. Keeping the percent moisture content

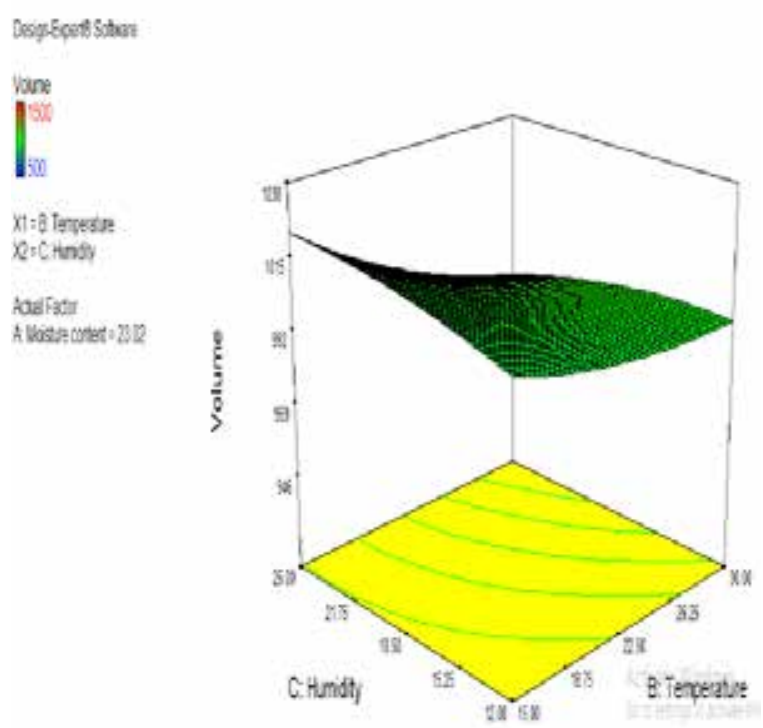

Fig. 8. Cross effect of humidity and temperature

constant at $23.02 \%$, the percent humidity increases as ambient temperature decreases. This is due to the fact that air tend to hold more water molecules as ambient temperature increases hence the relative humidity decreases. The optimum volume of the water required for irrigation is 1025 litres.

Figure 9 is a 3 D plot that studies the effect of the interaction of soil humidity and temperature on the need for irrigation as well as the volume of water required. As temperature increases, percent moisture content decreases. This is due to the fact that the rate of evaporation increases with increase in temperature with attendant decrease in the moisture content. The optimum value of the volume required for irrigation is 1060.9 litres. 


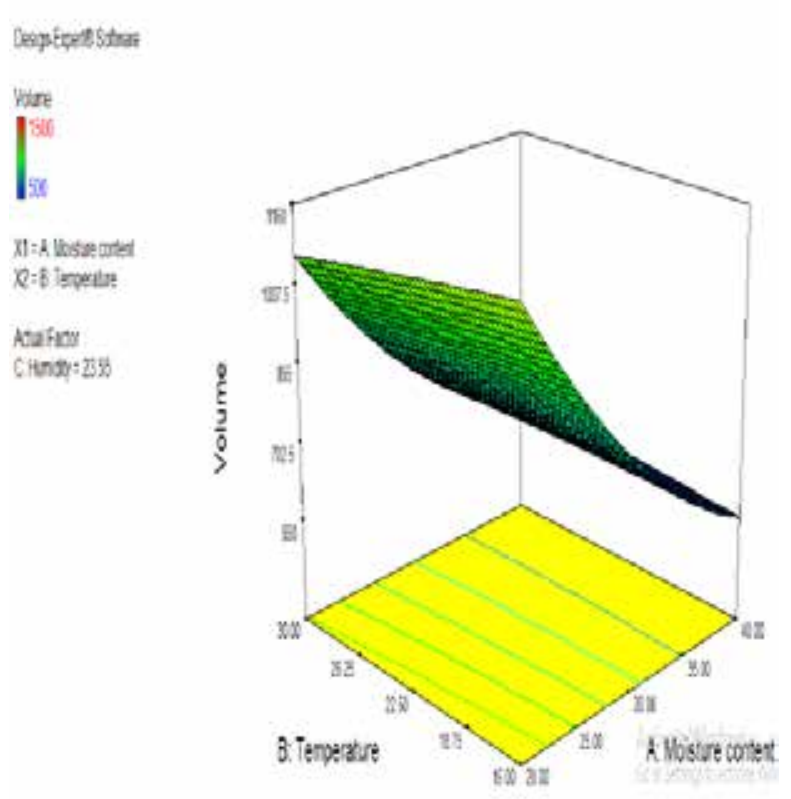

Fig. 9. Cross effect of temperature and moisture content

\section{Conclusion}

The development of the automated irrigated was successful carried out in a CAD environment and produced with the aid of additive manufacturing technique. It offers the benefits of improved farming practices via automation which enhances agricultural productivity and encourages round - the - year farming, efficient water distribution and management, while reducing the drudgery of manual labour, real time monitoring and control as well as proper scheduling of irrigation activities and enhances multiple mode of operation with query and feedback mechanism. The work is an improvement over existing work in that the ease of operation comes with its multiple modes of operation which affords user convenient choices of operation. Also, a predictive model that correlates the volume of required as a function of the soil moisture, air temperature and humidity was developed. This will assist in predicting the time necessary for irrigation as well as the volume of water required for the irrigation process.

\section{PUBLIC INTEREST STATEMENT}

This work is in line with the quest to improve food security via the deployment of appropriate technology for farm irrigation in order to improve crop yields and ease human drudgery. With the increasing awareness and advocacy for round-the-year farming, and the need to meet up with the global challenge of food demand, deploying appropriate technologies to increase productivity and to reduce the burden often associated with farm practices has become inevitable hence this work provides a standalone automated irrigation system which features good automation and control achieved using an array of electronic timing system, soil feedback sensor and wireless communication system.

\section{AUTHORS}

Lanre Daniyan* - NASRDA Centre for Basic Space Science, University of Nigeria, Nsukka, Nigeria.

Ezechi Nwachukwu - NASRDA Centre for Basic Space Science, University of Nigeria, Nsukka, Nigeria. Ilesanmi Daniyan* - Department of Industrial Engineering, Tshwane University of Technology, Pretoria, South Africa, E-mail: afolabiilesanmi@yahoo.com.

Okere Bonaventure - NASRDA Centre for Basic Space Science, University of Nigeria, Nsukka, Nigeria.

*Corresponding author

\section{REFERENCES}

[1] C. Angel and S. Ansha, "A Study on Developing a Smart Environment in Agricultural Irrigation Technique", The International Journal of Ambient Systems and Applications, vol. 3, no. 2/3, 2015, 11-17

DOI: 10.5121/ijasa.2015.3302.

[2] P. S. Bains, R. K. Jindal, and H. K. Channi, "Modeling and Designing of Automatic Plant Watering System Using Arduino", International Journal of Scientific Research in Science and Technology (IJSRST), vol. 3, no. 7, 2017, 676-680.

[3] D. S. Pavithra and M. S. Srinath, "GSM based Automatic Irrigation Control System for Efficient Use of Resources and Crop Planning by Using an Android Mobile", IOSR Journal of Mechanical and Civil Engineering, vol. 11, no. 4, 2014, 49-55 DOI: $10.9790 /$ 1684-11414955.

[4] A. M. Rasyid, N. Shahidan, M. O. Omar, N. Hazwani, and C. J. Choo, "Design and Development of Irrigation System for Planting Part 1", 2nd Integrated Design Project Conference (IDPC), 2015.

[5] B. D. Kumar, P. Srivastava, R. Agrawal, and V. Tiwari, "Microcontroller Based Automatic Plant Irrigation System", International Research Journal of Engineering and Technology, vol. 4, no. 5, 2017, 1436-1439.

[6] M. H. Razali, M. N. Masrek, and S. Roslan, "Microcomputer Application for Instrumentation Development in Drip Irrigation System", Journal of Computer Sciences and Applications, vol. 1, no. 3, 2013, 39-42

DOI: $10.12691 /$ jcsa-1-3-2.

[7] D. Kissoon, H. Deerpaul, and A. Mungur, "A Smart Irrigation and Monitoring System", International Journal of Computer Applications, vol. 163, no. 8, 2017, 39-45.

[8] J. M. Moreira Barradas, S. Matula, and F. Dolezal, "A Decision Support System-Fertigation Simulator (DSS-FS) for design and optimization of sprinkler and drip irrigation systems", Computers and Electronics in Agriculture, vol. 86, 2012, 111-119 DOI: 10.1016/j.compag.2012.02.015.

[9] J. Kumar, S. Mishra, A. Hansdah, and R. Mahato, "Design of Automated Irrigation System based on Field Sensing and Forecasting", Internation- 
al Journal of Computer Applications, vol. 146, no. $15,2016,17-21$

DOI: $10.5120 /$ ijca2016910938.

[10] S. Jadhav and S. Hambarde, "Android based Automated Irrigation System using Raspberry Pi", International Journal of Science and Research (IJSR), vol. 5, no. 6, 2016, 2345-2351 DOI: $10.21275 /$ v5i6.NOV164836.

[11] M. Dursun and S. Ozden, "A wireless application of drip irrigation automation supported by soil moisture sensors", Scientific Research and Essays, vol. 6, no. 7, 2011, 1573-1582.

[12] G. Nisha and J. Megala, "Wireless sensor Network based automated irrigation and crop field monitoring system". In: 6th International Conference on Advanced Computing (ICoAC), 2014, 189-194 DOI: 10.1109/ICoAC.2014.7229707.

[13] A. R. Al-Ali, M. Qasaimeh, M. Al-Mardini, S. Radder, and I. A. Zualkernan, "ZigBee-based irrigation system for home gardens". In: International Conference on Communications, Signal Processing, and their Applications (ICCSPA'15), Sharjah, 2015, 1-5 DOI: 10.1109/ICCSPA.2015.7081305.

[14] J. Haule, and K. Michael, "Designing and Simulation of an Automated Irrigation Management System Deployed by using Wireless Sensor Networks (WSN)", IOSR Journal of Electronics and Communication Engineering, vol. 9, no. 5, 2014, 67-73 DOI: $10.9790 / 2834-09526773$.

[15] A. F. Agbetuyi, H. E. Orovwode, A. A. Awelewa, S. T. Wara, and T. Oyediran, "Design and implementation of an automatic irrigation system based on monitoring soil moisture", Journal of Electrical Engineering, vol. 16, no. 2, 2016, 206-215.

[16] M. Ojha, S. Mohite, S. Kathole, and D. Tarware, "Microcontroller based automatic plant watering system", International Journal of Computer Science and Engineering, vol. 5, no. 3, 2016, 25-36.

[17] D. Dharrao, L. Kolape, S. Pawar, and A. Patange, "Automated Irrigation System using WSN", Asian Journal of Engineering and Technology Innovation, vol. 3, no. 6, 2015, 18-21.

[18] S. Malge and K. Bhole, "Novel, low cost remotely operated smart irrigation system". In: International Conference on Industrial Instrumentation and Control (ICIC), 2015, 1501-1505 DOI: 10.1109/IIC.2015.7150987.

[19] P. Archana and R. Priya, "Design and Implementation of Automatic Plant Watering System", International Journal of Advanced Engineering and Global Technology, vol. 4, no. 1, 2016, 1567-1570.

[20] M. S. Manoj and B. Hemalatha, "Automatic irrigation using microcontroller basing on pressure", International Journal of Pure and Applied Mathematics, vol. 116, no. 20, 2017, 349-353.

[21] V. N. R. Gunturi, "Micro Controller Based Automatic Plant Irrigation System", International Journal of Advancements in Research \& Technology, vol. 2, no. 4, 2013, 194-198.

[22] A. Curtis, "Smart irrigation". In: L.D. Currie and L.L Burkitt, eds., Moving farm systems to improved attenuation, Occasional Report No. 28. Fertilizer and Lime Research Centre, Massey University, Palmerston North, New Zealand, 2015, http:// flrc.massey.ac.nz/publications.html.

[23] L. Karim, A. Anpalagan, N. Nasser, and J. Almhana, "Sensor-based M2M Agriculture Monitoring Systems for Developing Countries: State and Challenges", Network Protocols and Algorithms, vol. 5 , no. 3, 2013, 68-86

DOI: $10.5296 /$ npa.v5i3.3787.

[24] P. Alagupandi, R. Ramesh, and S. Gayathri, "Smart irrigation system for outdoor environment using Tiny OS". In: International Conference on Computation of Power, Energy, Information and Communication (ICCPEIC), 2014, 104-108 DOI: 10.1109/ICCPEIC.2014.6915348.

[25] J. Gutiérrez, J. F. Villa-Medina, A. Nieto-Garibay, and M. Á. Porta-Gándara, "Automated Irrigation System Using a Wireless Sensor Network and GPRS Module", IEEE Transactions on Instrumentation and Measurement, vol. 63, no. 1, 2014, 166-176 DOI: 10.1109/TIM.2013.2276487.

[26] M. S. Gavali, B. J. Dhus, and A. B. Vitekar, "A Smart Irrigation System for Agriculture Based on Wireless Sensors", International Journal of Innovative Research in Science, Engineering and Technology, vol. 5, no. 5, 2016, 6893-6899.

[27] D. K. Roy and M. H. Ansari, "Smart Irrigation Control System", International Journal of Environmental Research and Development (IJERD), vol. 4, no. 4, 2014, 371-374.

[28] Dan Bai and Wei Liang, "Optimal planning model of the regional water saving irrigation and its application". In: International Symposium on Geomatics for Integrated Water Resource Management, 2012, 1-4 DOI: 10.1109/GIWRM.2012. 6349622.

[29] T. Li-Fang, "Application of autocontrol technology in water-saving garden irrigation". In: International Conference on Computer Science and Information Processing (CSIP), 2012, 1311-1314 DOI: 10.1109/CSIP.2012.6309103.

[30] S.Lucksman,P.Subramaniyam,H.Suntharalingam, S. G. S. Fernando, and C. D. Manawadu, "Ralapanawa RND - Automated water management system for Irrigation Department, Sri Lanka". In: 8th International Conference on Computer Science Education, 2013, 213-217 DOI: 10.1109/ICCSE.2013. 6553912.

[31] L. Gao, M. Zhang, and G. Chen, "An Intelligent Irrigation System Based on Wireless Sensor Network and Fuzzy Control", Journal of Networks, vol. 8, no. 5, 2013, 1080-1087

DOI: $10.4304 /$ jnw.8.5.1080-1087.

[32] S. V. Devika, S. Khamuruddeen, S. Khamurunnisa, J. Thota, and K. Shaik, "Arduino Based Automatic Plant Watering System", International Journal of Advanced Research in Computer Science and Software Engineering, vol. 4, no. 10, 2014, 449-456.

[33] K. Kansara, V. Zaveri, S. Shah, S. Delwadkar, and K. Jani, "Sensor based Automated Irrigation System with IOT: A Technical Review", Internation- 
al Journal of Computer Science and Information Technologies, vol. 6, no. 6, 2015, 5331-5333.

[34] D. Rane, P. R. Indurkar, and D. M. Khatri, "Review paper based on automatic irrigation system based on RF module", International Journal of Advanced Information and Communication Technology, vol. 1, no. 9, 2015, 736-738.

[35] F. A. Morrison, An introduction to fluid mechanics, Cambridge University Press: Cambridge; New York, 2013.

[36] R. K. Rajput, A Textbook of Fluid Mechanics, S. Chand Limited, India, 2008, 